\title{
DESIGN OF FARMING ROBOT FOR WEED DETECTION AND HERBICIDES APPLICATIONS USING IMAGE PROCESSING
}

\author{
Shraddha S. Durugkar ${ }^{1}$, Priyanka S. Jadhav ${ }^{2}$, Shraddha S. Zade ${ }^{3}$, Vijay S. Bhong ${ }^{4}$ \\ ${ }^{l}$ BE Students, Dept. of ENTC, SVERI's COE, Pandharpur, India \\ ${ }^{2} B E$ Students, Dept. of ENTC, SVERI's COE, Pandharpur, India \\ ${ }^{3} B E$ Students, Dept. of ENTC, SVERI's COE, Pandharpur, India \\ ${ }^{4}$ Assistant Professor, Dept. of ENTC, SVERI's COE, Pandharpur, India
}

\begin{abstract}
The main aim of the implementation is the agriculture system by spraying the herbicides to the unnecessary weeds present in the farm field. Weed present in the field reduces the quantity and the quality of the crops and reduce the profit of the farmers. Almost all the Indians are dependent on Agriculture and up to $70 \%$ of the population depends on the Agriculture directly or indirectly. In India, 349 million acres of area are under cultivation. India is the top 7th net exporting nation across the globe in the Agricultural Goods, thus Agriculture plays a key role in the Indian Economics. Agriculture is a backbone of human life. In this paper we implemented image processing using MATLAB to detect the weed areas in an image of farm fields.
\end{abstract}

Keywords: Image Processing, Agriculture, Weed Detection, Spraying Pump

\section{INTRODUCTION}

Agriculture is a field which requires automation in its various applications. New advanced technology is used in the agricultural operation due to labor shortage. Increased use of herbicide affects the health of the human beings and animals, etc. Agriculture operation needs automation, among this one is weed control. In olden days weed control system, herbicide is sprayed uniformly over the field which may damage crop condition. Apart from that, there is a negative impact on the plant, soil large amount of herbicides are wasted and it is sprayed only in some part of the weed in the field. In this paper our main aim is to detect the weed in the crop by using image processing. Then we will give the inputs of the weed areas to an automatic spray pesticide only in those areas with the help of the Robot. For this we need to take a photograph of the field with good clarity to detect the weeds with good accuracy. Taking a photograph can be done by the camera taking them manually. Then we will apply image processing to that image using MATLAB to detect the weed. Based recent research of the weed science, mostly $33 \%$ of the losses in the on the agricultural field can be caused by the unwanted weeds only.

\subsection{Related Work on Weed Detection}

There are a few approaches exist that, may be used in our solution, try to solve the problem of weed detection. These approaches to protect the crop while plants grow up on the farm. Weed detection is now a big challenge for every farmer; it causes maximum loss of crop and decrease the productivity of farming.

\section{METHODOLOGY}

This method proposes a system which is capable of detecting weed on the basis of color base segmentation. This system creates an awareness in the automation system. It consists of RF Transreceiver based control system that transmits the wireless signals according to the input being selected based on color detected by the MATLAB section. The system consists of the following basic systems:(i) weed detection (ii) MATLAB section (iii) wireless transmission system (iv) Robotic section (v) herbicide spraying System.

\subsection{MATLAB Section}

The weed detection is the first step by using a camera. The image acquisition is the first step that takes place in MATLAB. The acquisition can be done by digital camera such as normal webcams. The webcam should be installed perpendicular to ground. The output images of the webcam are in RGB format with a size of $640 * 480$ pixels. After that the acquired images are processed in MATLAB. Colour segmentation is done here.

\subsection{Robotic Section}

To achieve the goal of reducing the pesticide usage, spraying the herbicide on the weed areas. The sprayer used for the herbicide spraying may be the robotic hand or the sprinkler etc. Depending upon the requirement the sprayer is designed either to operate manually or automatically. For classifying the weeds and crops in the agricultural field many algorithms are used in the existing model. Various algorithm techniques are available to detect the presence of weeds from the crops. Most of the available techniques are done using image processing method. To reduce the usage 
of herbicide and the correct identification of the weed so this system is implemented. Since it is a user friendly technique. The major difference between the existing and the proposed model is the major classification accuracy and the amount of the herbicide spraying in the field areas.

\section{ALGORITHM}

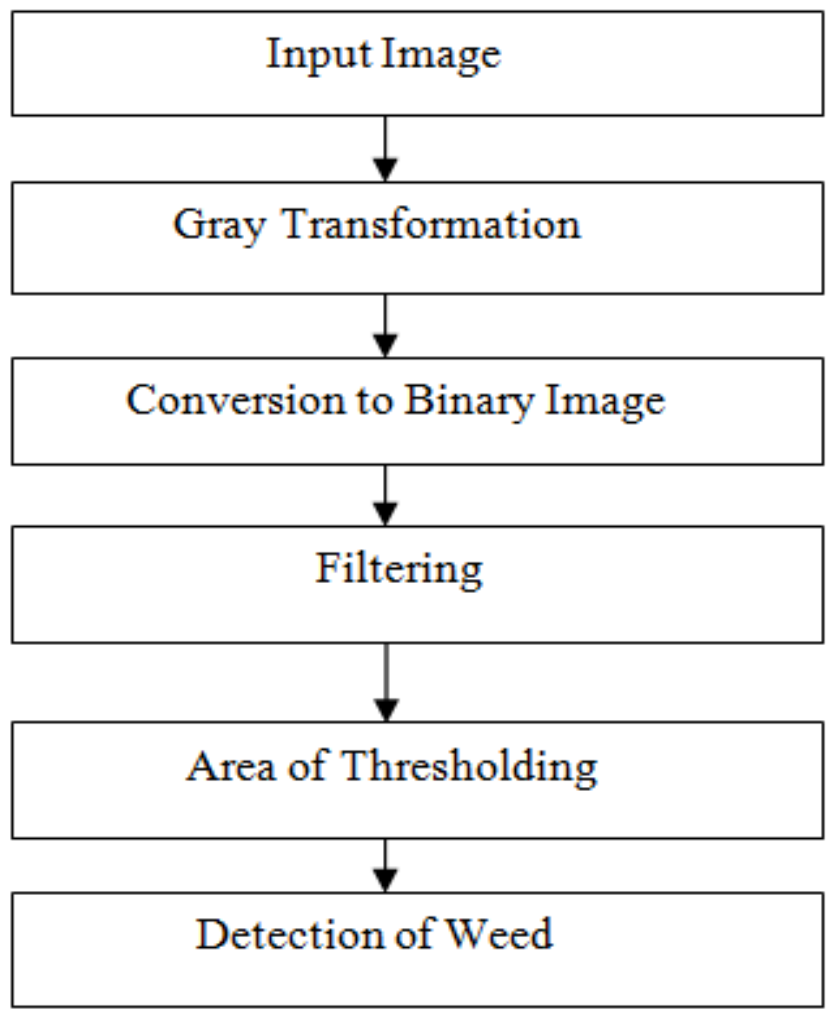

Fig -1: Algorithm for Weed Detection

The weed and crop, color images are obtained through the digital camera. The sample images are taken from the fields. The gray transformation processing is to turn the color image to the gray image. The purpose of gray transformation is to reduce the amount of color data in the image so as to speed up the following processing. To remove background of the image, different techniques such as thresholding based segmentation, edge base segmentation, Color based segmentation and watershed segmentation can be used. The grayscale image is converted into binary image from the preprocessing stag. Thresholding based on gray image is used to change the binary image. The final segmented image is used as the input of the weed and crop classification stage.

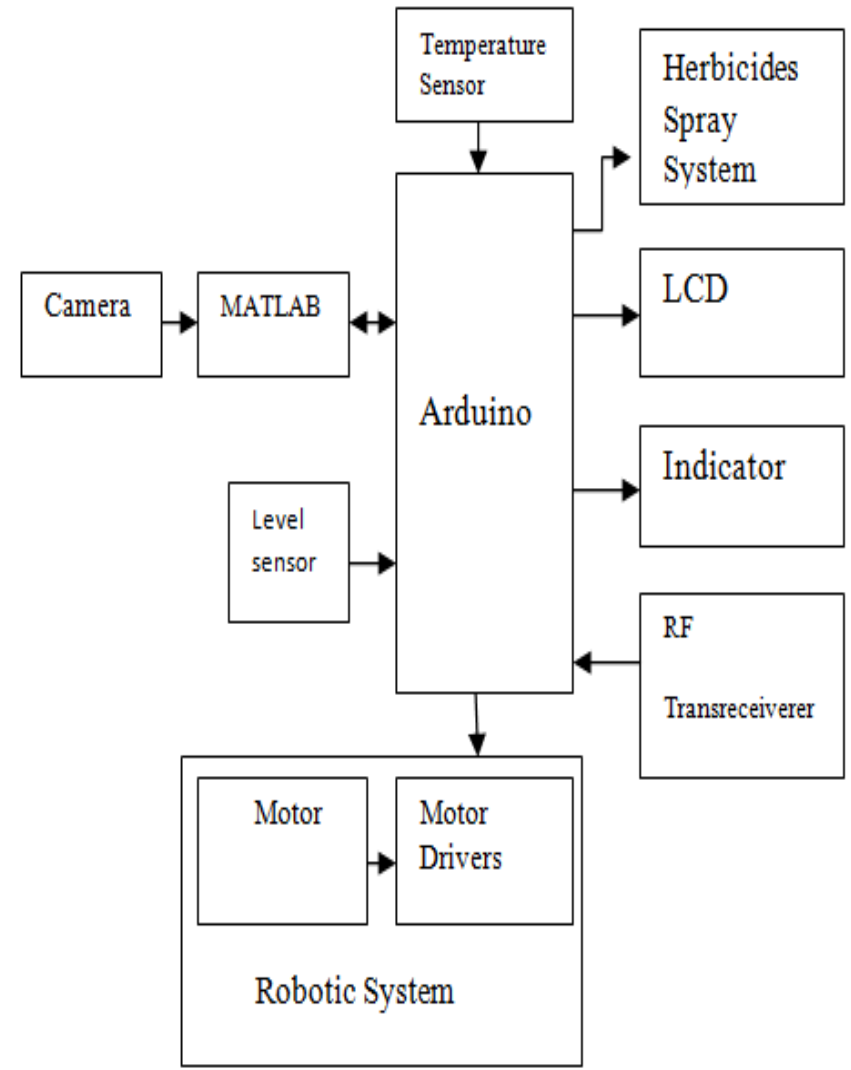

Fig-2: Overall system Block Diagram

\section{CONCLUSION}

From the literature survey, we have studied the difference between crop and weed. By using MATLAB software we can detect weed. Due to the use of our system, we can detect and separate out weed affected area from the crop plants. The obtained results are then analyzed, from these results, weeds are identified after it is analyzed which is controlled by the Arduino. Arduino gave the signal to motor to actuate the system and it will spray the herbicides on weed. By doing so we can reduce the usage of labour work, thus saving the time.

\section{ACKNOWLEDGEMENT}

We would like to express our sincerely gratitude to all those who provided us the possibility to complete this project. A special gratitude we give to our final year project guide, $\mathrm{Mr}$. Vijay S. Bhong, whose contribution in stimulating recommendation and motivation, helped us to coordinate our project, especially in writing this Journal.

\section{REFERENCES}

[1] Su Hnin Hlaing1, Aung Soe Khaing2, “weed and crop segmentation and classification using area thresholding", IJRET: International Journal of Research in Engineering and Technology eISSN: 2319-1163 pISSN: 2321-7308.

[2] Ajinkya Paikekari1, Vrushali Ghule2, Rani Meshram3, V.B. Raskar ${ }^{4}$, “ weed detection using 
image processing", International Research Journal of Engineering and Technology (IRJET) Volume: 03 Issue: 03 March-2016.

[3] Dr. V. S. Malemath, "A new approach for weed detection in agriculture using image processing techniques", International Journal of Advanced Scientific and Technical Research Issue 6 volume 3, May - June 2016.

[4] Ayswarya.R1, Balaji.B1, Balaji.R1, Arun.S1, Ramya.R2, "Weed Detection in Agriculture Using Image Processing", International Journal of Advanced Research in Electrical, Electronics and Instrumentation Engineering Vol. 6, Issue 3, March 2017. 